\title{
Platform Development for Drone Utilization in the Architectural Field
}

\author{
Hiroyuki Miyauchi
}

\author{
Department of Building Materials and Components, Building Research Institute, 1 Tachihara, \\ Tsukuba-shi, Ibaraki, 305-0802, Japan, miyauchi@kenken.go.jp
}

\begin{abstract}
The utilization of drones is expected to streamline the process of building inspection in Japan; however, no known drone utilization platform exists in the region's architectural sector. Therefore, in this study we pioneered the development of a drone platform based on an industrygovernment-academia collaboration within Japan's architectural field. We first investigated dronerelated trends, such as a utilization roadmap, flight rules, the drone market, new technologies and issues relating to the architecture field. Subsequently, we worked on solutions for drone utilization in the building sector, including methods for building inspection, determination of drone-flight risk factors relative to building inspection and the creation of a drone safety operation manual. Through field tests, we validated the effectiveness of the drone platform in building inspection, i.e., the determination of a cost-time relation during inspection, the merits of applying a high-resolution camera for inspection, the possibility of utilizing an infrared camera for exfoliation detection in exterior wall tiles and the development and efficiency of a built-in automatic inspection system. Furthermore, trial tests were conducted for the application of a drone-inspection system in disaster areas and a micro-drone in small building spaces. The findings of this study confirmed that the new drone platform achieved inspection-and disaster-related objectives within the architectural sector.
\end{abstract}

Keywords: Drone, Industrial Advances, Building Inspection, Risk Assessment, Field Test.

\section{Introduction}

In Japan, the total number of pre-1980 housing stocks exceeds 13.69 million and is increasing every year. To ensure longevity, the assessment of buildings and their required maintenance has become an urgent issue. As such, efficient regular inspections are required as an important component of building maintenance. For example, periodic inspection reports according to Article 12 of the Building Standards Law are required for building health diagnosis. For the exterior wall inspection of buildings, a manual hammering test is required, especially for buildings that are more 10 years old. However, this test requires the setting up of temporary scaffolding for areas that cannot be reached by the investigator, making it costly for the building owner. There is an urgent need to develop a rational inspection method. In meeting this requirement, the use of drones is expected to play a significant role. An inspection technology for the maintenance of such buildings, the various potential uses of drones are being explored.

In 2016, the authors began research on (i) building inspection technology using drones and (ii) the construction of drone platforms. In the academic field, the Architectural Institute of Japan (AIJ) established a committee relating to the use drones and held the Architectural Drone Symposium to establish the current state of the art in drone usage. In the industrial field, the Japan Architectural Drone Association (JADA) was established in 2017 to address human resource development, technical support and standardization relating to the safe use of 
drones. JADA has organized workshops and committees covering the safe operation of drones. In general, the use of drones in industry, government, and academia is gradually increasing.

Based on the above background, we herein report on (i) drone-related trends and levels of technology in the architectural field, (ii) demonstration experiments related to drone inspections and (iii) future prospects for drone usage.

\section{Trends in the Use of Drones in the Architectural Field}

\subsection{Drone Technology Trends in Japan}

As seen for Japan during 2018 (Figure 1), the use of drone services in sectors such as agriculture, surveying, aerial photography, inspection, crime prevention and logistics is expanding. Furthermore, by 2024 the infrastructure inspection sector is expected to outpace the agricultural sector. Figure 2 shows the roadmap for the utilization of drones according to the flight levels reported by the Ministry of Economy, Trade and Industry (METI). Level 1 corresponds to surveys such as those of a detached roof. Level 2 corresponds to a large area roof inspection or wall inspection. Level 4 is expected to be used for (i) the inspection of skyscrapers that are assumed to be non-visual flight in the 2022, (ii) logistics and security in cities and (iii) disaster-related issues. Therefore, in the architectural field, it is necessary to create a social infrastructure that assumes the use of drones in population-intensive areas. Table 1 shows the uses of drones in the architectural field. From all the papers submitted up to 2018, the importance of drone use follows the order: inspection, disaster, city/region,
construction, environmental measurement, transportation and culturalleritage.
In particular, the use of drones for inspection is inereasing, particularly in relation to the
inspection of the outer walls of high-rise buildings, which would otherwise require
scaffolding. These building inspection surveys are generally classified into primary to tertiary
surveys according to the level of inspection, as shown in Table 2. Currently, primary and

secondary surveys of a non-contact type are used for building inspection.

Register for free at https//www.scipedia.com to download the version without the watermark

2.2 Drone Techmology Development and Dissemimation Efforts in the Architectural Academic Field

In April 2016, "WG on Application Guide of UAV to Building Performance Survey"

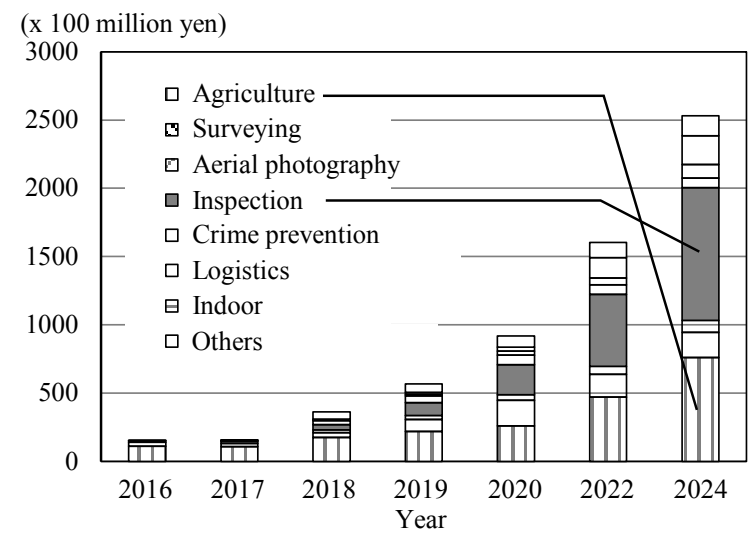

Figure 1. Drone service market in Japan.

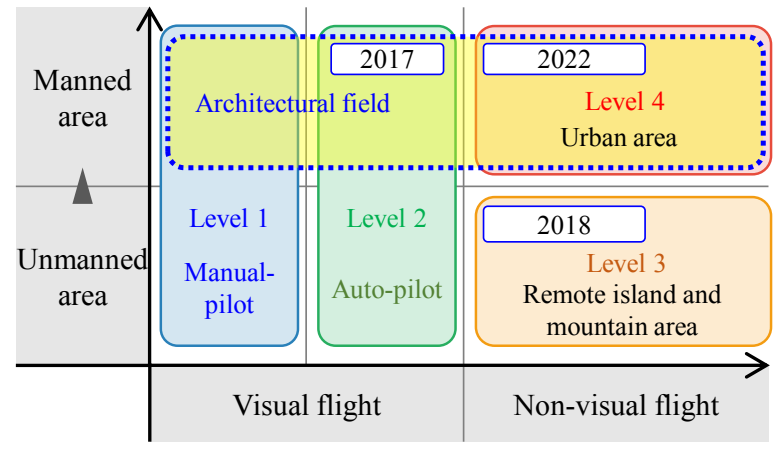

Figure 2. Utilization in architectural field at different flight levels. 
(currently, Sub-committee for utilization of drone technology; Chairperson: H. Miyauchi) was established in the Durability and Maintenance Steering Committee, AIJ. The main foci of this WG were (i) the use of drones for the survey of building exterior walls, (ii) the collection of technical information, (iii) field trials and (iv) the examination of data collection and analysis methods. In May 2017, the first Architectural Drone Symposium was held with the aim of highlighting the advantages of drone technology across the entire architectural field. In 2019, a third symposium provided the latest information on the use of drones, covering regular use through to their use in disaster situations.

\subsection{Challenges and Initiatives for the Utilization of Drones in the Construction Industry}

The challenges facing the use of drones in the architectural field can be divided into (i) the damage caused by drone collisions and (ii) human issues. Regarding (i), Figure 3 shows the number of accidents caused by drones, based on information provided to Ministry of Land, Infrastructure, Transport and Tourism (MLIT). Compared with the 45 accidents for which no application for flight was required by the MLIT, 96 accidents (i.e., more than double) did require an application for flight. In particular, there are many population-intensive areas assumed during surveys of buildings and accidents when flying less than $30 \mathrm{~m}$, and so sufficient safety measures are required when using drones in urban and architectural areas. Regarding (ii), there is a risk that video taken by drones may infringe privacy, as related to the
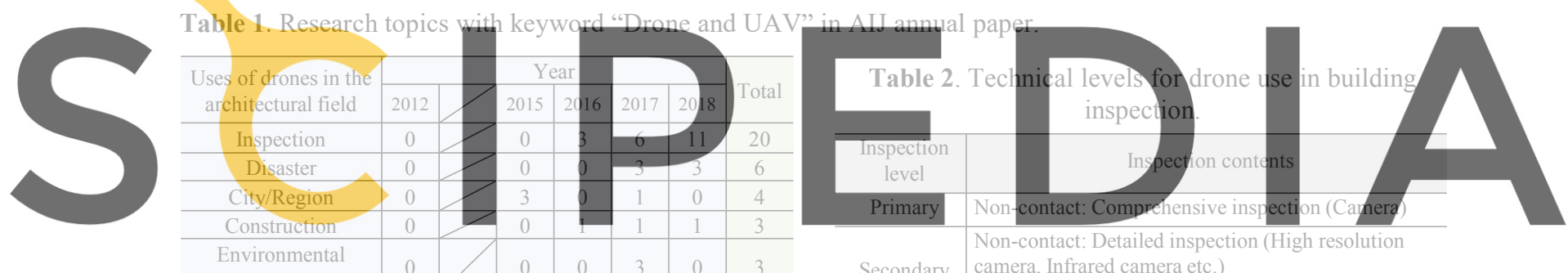

Register for freseathithtps//WWW.Scipedia.com ${ }_{2}$ to downloadpithetsversioneswithouttothe envatermark \begin{tabular}{c|c|c|c|c|c|c|c}
\hline Cultural heritage & 1 & 0 & 0 & 0 & 0 & 1 \\
\hline Total & 1 & 3 & 4 & 15 & 16 & 39 \\
\hline
\end{tabular}

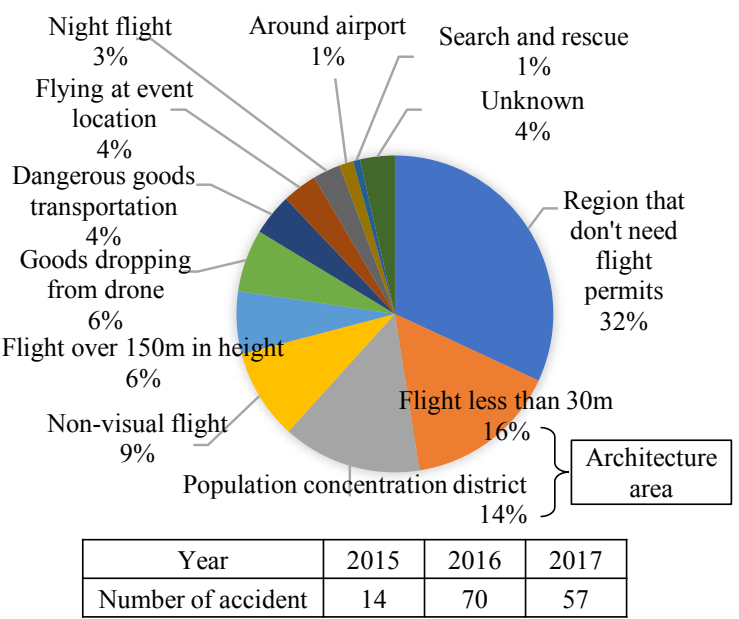

Figure 3. Number of accidents caused by drones (as of December 8, 2017).

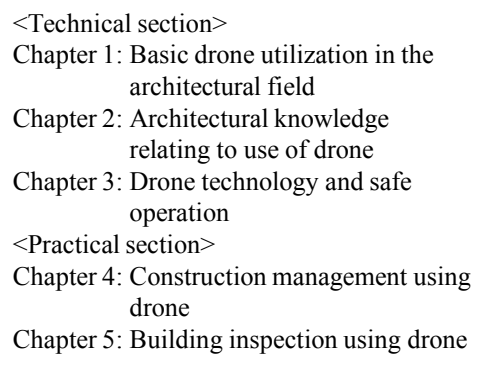

$<$ Technical section $>$

Chapter 1: Basic drone utilization in the architectural field

Chapter 2: Architectural knowledge relating to use of drone

Chapter 3: Drone technology and safe operation

$<$ Practical section $>$

Chapter 4: Construction management using drone

Chapter 5: Building inspection using drone
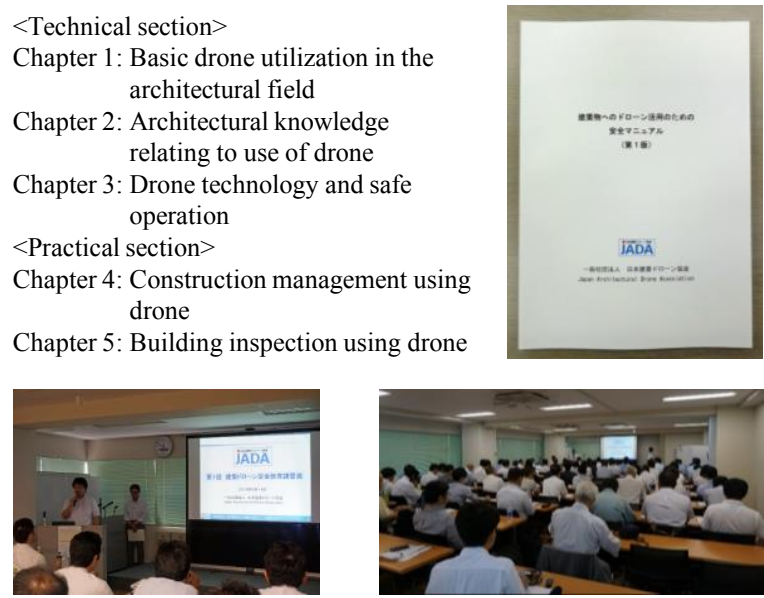

Figure 4. Safety Manual for Drone Utilization in Buildings and safety education workshop. 
Personal Information Protection Law. There are also problems relating to noise during drone flight; therefore, it is necessary to give sufficient consideration to residents.

Against this background, JADA was established in September 2017 to develop human resources that can utilize drone technology across various applications in the architectural field. JADA also provides technical support and standardization. Activities were commenced with the aim of contributing to the realization of a safe, secure and sustainable society when conducting business. In particular, we are strengthening efforts relating to the safe operation of drones for building inspections. For example, as shown in Figure 4, the "Safety Manual for Drone Utilization in Buildings" was created, explaining basic knowledge relating to (i) drone utilization, (ii) drone technology and safe operation and (iii) construction management and inspection surveys for buildings. In addition, this manual is used in the "Building Drone Safety Education Workshop" to ensure thorough safety education.

\section{Evaluation of Building Inspection using Drones}

\subsection{Effects of Cost and Time during Drone Inspection Surveys}

Judgment criteria that show the superiority of drone usage over existing building inspections include (i) cost and time requirements from inspection to analysis and (ii) whether or not the level can be inspected under the same conditions as it can from the ground. From the above, using a six-story experimental wooden house at the Building Research Institute (BRI), the
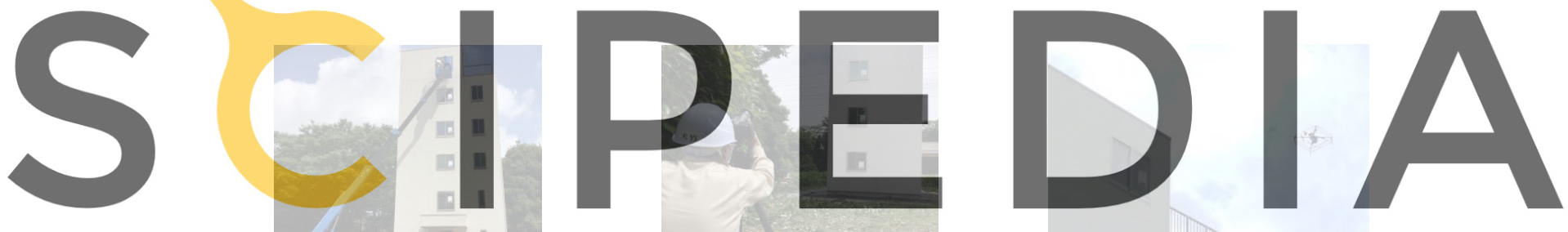

Register for free at https//www.scipedia.com to download the version without the watermark work vehicle

Figure 5. Inspection methods

Table 3. Visualization of buildings by drone.

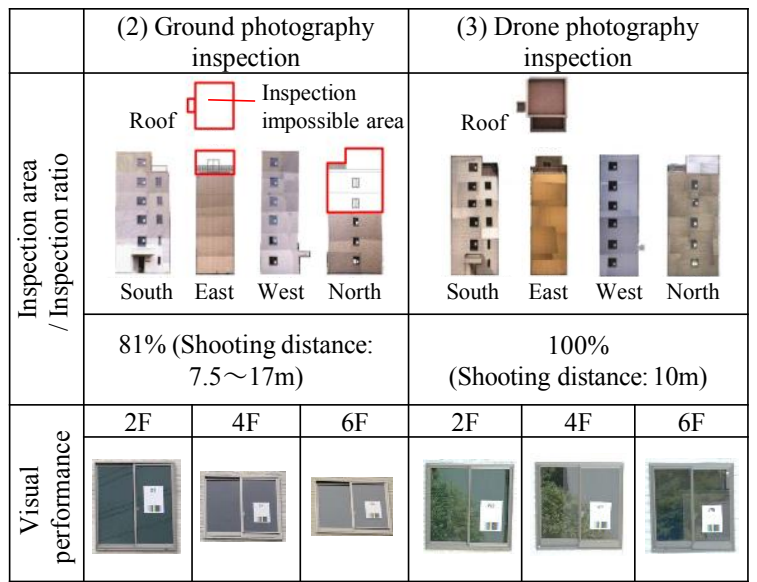

(a) Cost

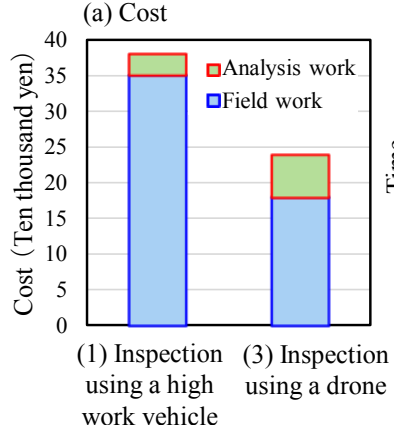

(b) Work time

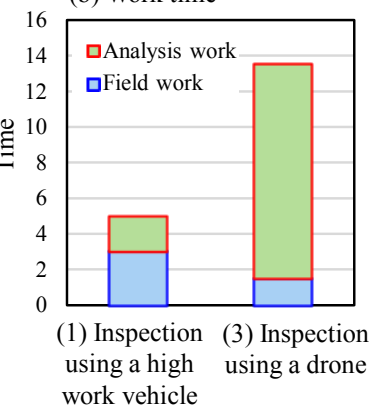

Figure 6. Comparison of cost and time requirements for high level manual inspection and drone photography inspection. 
advantages of using a drone for building inspection were evaluated by comparison with a conventional inspection, as shown in Figure 5. Table 3 shows the results of comparing (2) ground photography and (3) drone photography. If a drone can secure a safe flight distance from a target object, it can photograph to the same accuracy as a visual inspection from the ground. For example, because the image size and image quality of the object can be kept constant during photographing by the drone, it is easy to subsequently analyze the image.

Figure 6 shows the results of comparing the cost and time requirements between (1) inspection using a high work vehicle and (3) inspection using a drone. Inspection by drone photography can be implemented at a lower price than that for a high work vehicle. On the other hand, the cost and time of image processing of drone images is higher; in particular, the analysis work is time consuming. These finding indicate the potential efficiency of on-site drone inspections but also suggest that image processing needs to be simplified and incorporate automated processing techniques.

\subsection{Assessment of the Use of a High Resolution Camera}

One of the important criteria that can be applied to building inspections is inspection accuracy in relation to specified requirements. Therefore, using a general-purpose 20-million pixel camera and a 100-million pixel camera (upper limit of resolution), we conducted a drone photographing experiment to evaluate the building inspection accuracy. Table 4 shows the performance values of the cameras used in the study. Figure 7 shows the visibility results of both cameras when a crack sqaie is attached to the outer wall and the drone flight shown i Figure 8 is taken. At a photographing distance of $5 \mathrm{~m}$, it is difficult to see a crack when using the 20-million pixel canera. However confirmation is possible
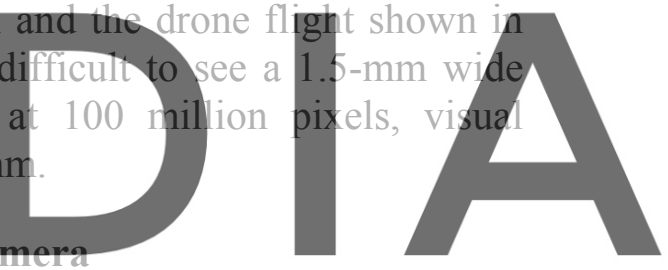

When tiles are used for the exterior of a building there is a risk of them peeling off due to a an expected inspection method is the use of a drone-mounted infrared ray camera. A demonstration experiment of this approach was conducted by MLIT in 2017-2018. At BRI,

Table 4. Specifications to satisfy 1-mm/pixel resolution

\begin{tabular}{c|c|c}
\hline Performance & 100-million pixel camera & 20-million pixel camera \\
\hline Distance & $32.6 \mathrm{~m}$ & $13.7 \mathrm{~m}$ \\
\hline $\begin{array}{c}\text { Photography } \\
\text { area }(\mathrm{H} \mathrm{x} \mathrm{W})\end{array}$ & $8.7 \mathrm{~m} \mathrm{x} 11.6 \mathrm{~m}$ & $5.3 \mathrm{~m} \mathrm{x} 4.0 \mathrm{~m}$ \\
\hline Viewing angle & $15.2^{\circ}$ & $16.4^{\circ}$ \\
\hline
\end{tabular}

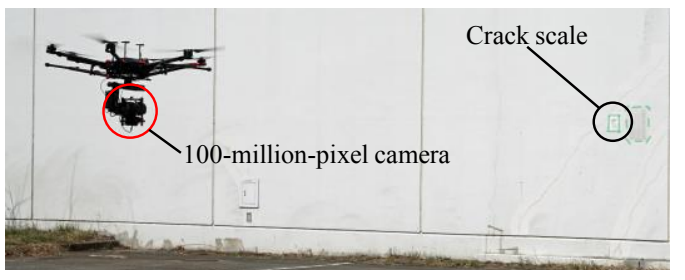

Figure 7. Inspection test by drone.

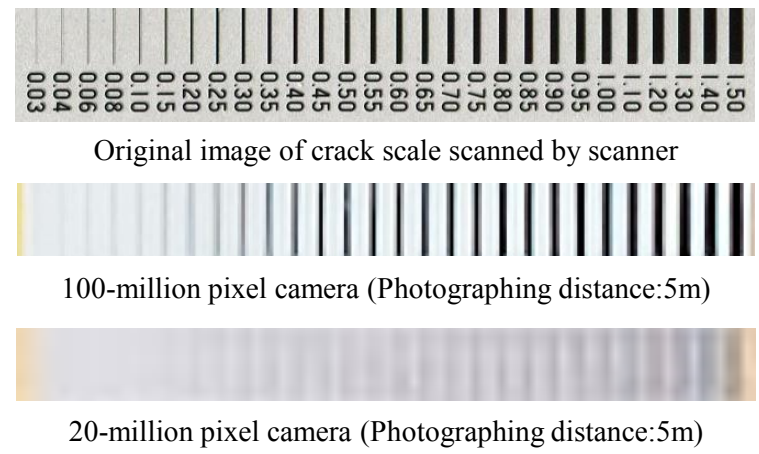

Figure 8. Images from different resolution cameras. 
the test specimens included defect part between substrate and tile with $1 \mathrm{~m}$ wide $\mathrm{x} 1 \mathrm{~m}$ high were made as parameters with defect area and peeling depth. As shown in Figure 9, these specimens were placed on the roof of the building and aerial photographs were taken using two types of infrared camera mounted on a drone. An example of the detection of the defective part of a tiled specimen, as shown in the infrared image, is shown in Figure 10. When environmental conditions, such as solar radiation and temperature, and the performance of the applied infrared camera were appropriate, the detection rate of tile peeling was high. However, it was found that it is important to define the application range when using a dronemounted infrared camera because the peeling conditions and photographic environment may differ in an actual building.

\subsection{Development of Automatic Inspection and a Building Inspection System}

Although drones are generally controlled by GPS, it is difficult to capture GPS signals in areas where buildings are densely packed, increasing the risk of crashing and potentially decreasing building inspection accuracy. In this study, we used SLAM (Simultaneous Localization and Mapping), as shown in Figure 11, which estimates the position of the camera based on the image information of the camera (i.e., independent of GPS signal). Figure 12 shows the results of a demonstration experiment of automatic drone inspection using an

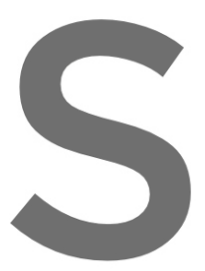

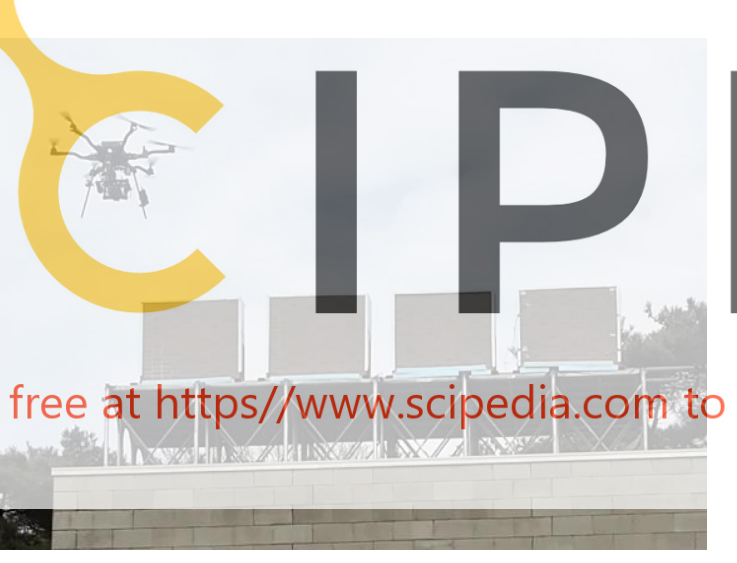

Figure 9. Inspection of tiled specimens using drone.

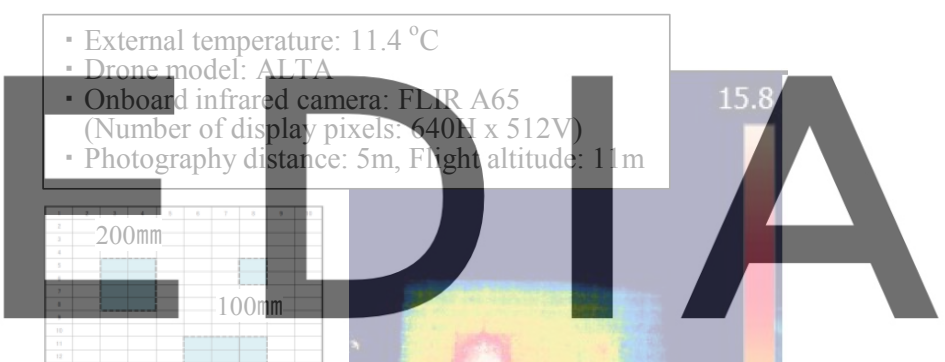

download the version without the watermark

Specimen (Peeling depth between substrate and tile : $1 \mathrm{~mm}$ )

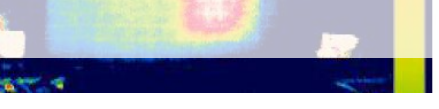

Figure 10. Inspection of defective parts of tile specimens by drone-mounted infrared camera.

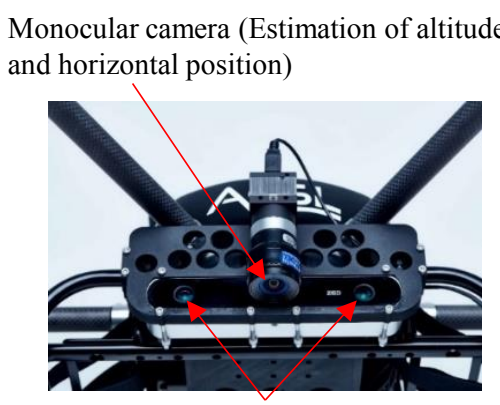

Twin-lens stereo camera (Horizontal distance control)

Figure 11. Visual SLAM type drone.

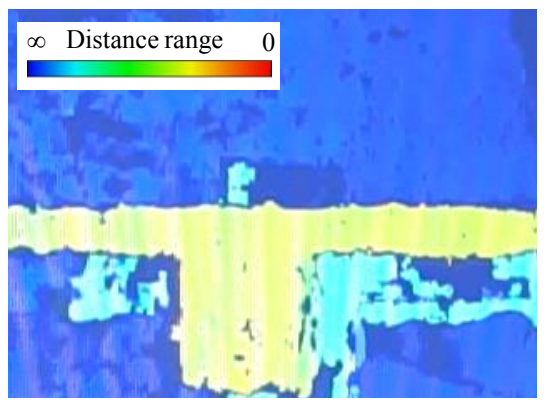

Color information to maintain a distance from the drone

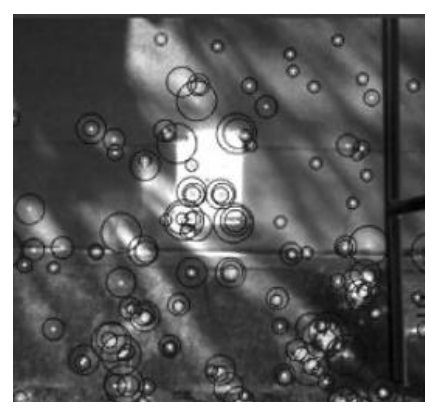

Self-position estimation of horizontal direction by monocular camera

Figure 12. Test results for drone with Visual SLAM technology. 
experimental building. The left of Figure 12 shows the use of a stereo camera to identify distance based on color information while maintaining a distance of $3 \mathrm{~m}$ from the drone. Furthermore, a downward camera was able to estimate self-position in the horizontal direction of the drone flight based on characteristic points on the asphalt pavement surface, as shown on the right of Figure 12.

\subsection{Use for Data Recording and Analysis}

It is important to record and measure building deterioration information on a regular basis. This information then needs to be stored and later used for building maintenance as required. Therefore, in Figure 13 we show an example of recording and storing deterioration information relating to a waterproof membrane sheet on the building roof. The resolution of the image was set to $1.2 \mathrm{~mm} / \mathrm{pixel}$ and the altitude was set to $38 \mathrm{~m}$ from the roof. The entire roof surface was photographed during an automatic flight and a series of deterioration conditions for the roof were acquired. As shown in Figure 14 (m units), the flow of drainage on the waterproof sheet and the roof area could be measured. In cm units, the situation around the drain was able to confirm, in mm units, the crack and repair status of the waterproofing sheet. Therefore, it is possible to simultaneously record these states of degradation using a drone and archive them for use in future repairs.

\subsection{New Methods for Building Inspection}
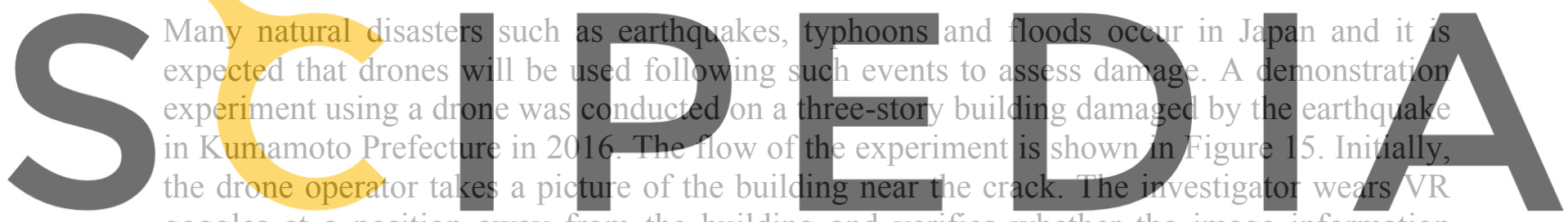
goggles at a position away from the building and verifies whether the image information

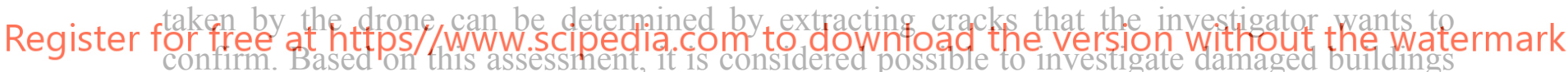
via drone by remote control.

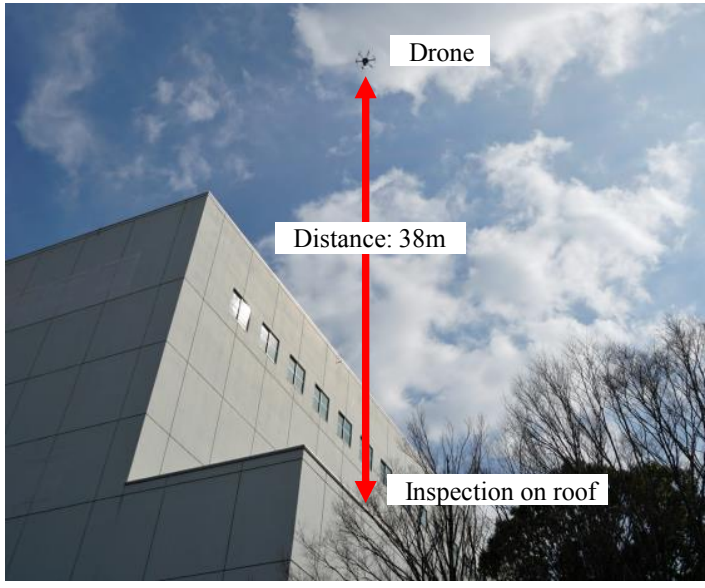

Figure 13. Flight test for checking degradation condition using drone.

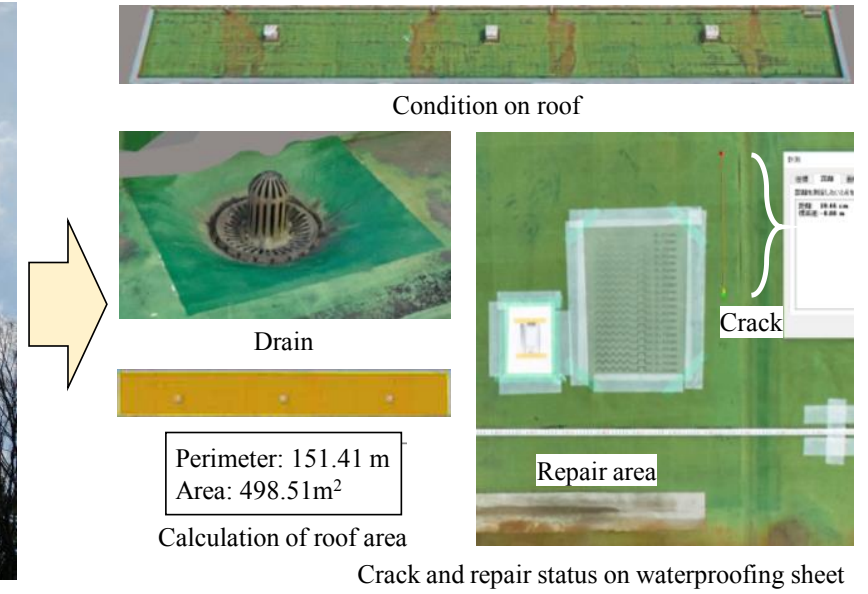

Figure 14. 3D model of degradation information (100-million pixels). 


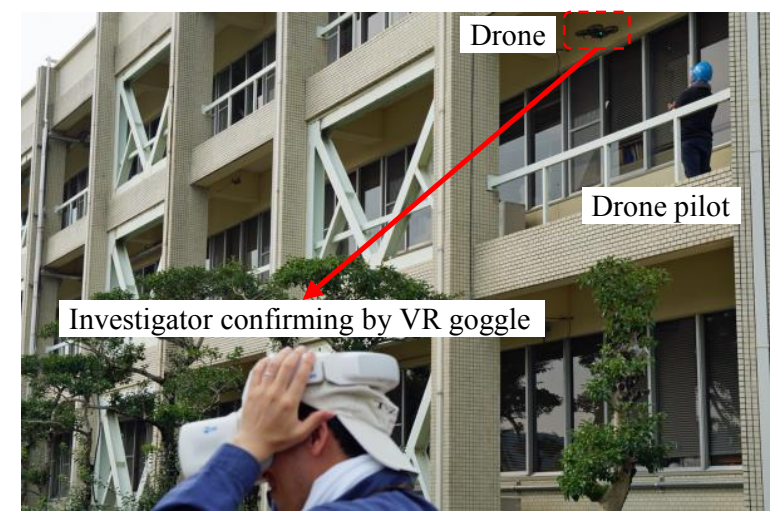

Figure 15. Remote investigation by drone in damaged building.

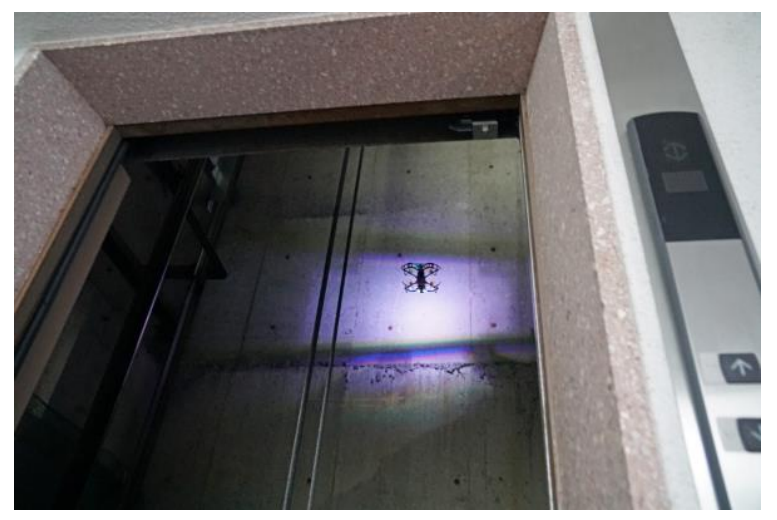

Figure 16. Drone inspection in confined space (elevator shaft).

Many external spaces related to buildings can be assessed using drones; however, drones are also highly usable in narrow spaces where human access is difficult, e.g., behind ceilings and under floors. Therefore, in this study, we investigated the inner wall of an elevator shaft using a micro drone with a non-GPS control function that weighs less than $200 \mathrm{~g}$, as shown in Figure 16. It was found that this approach can be used for inspection even in dark and confined spaces.

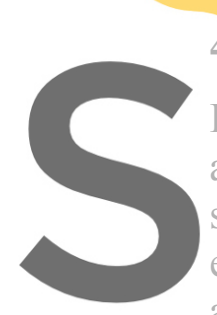

\section{Conclusions}

In this study, we investigated application to the architectural saving, inspection accuracy, application to evaluated by field tests. Overall, the effective addition to building inspection, drone technologyr
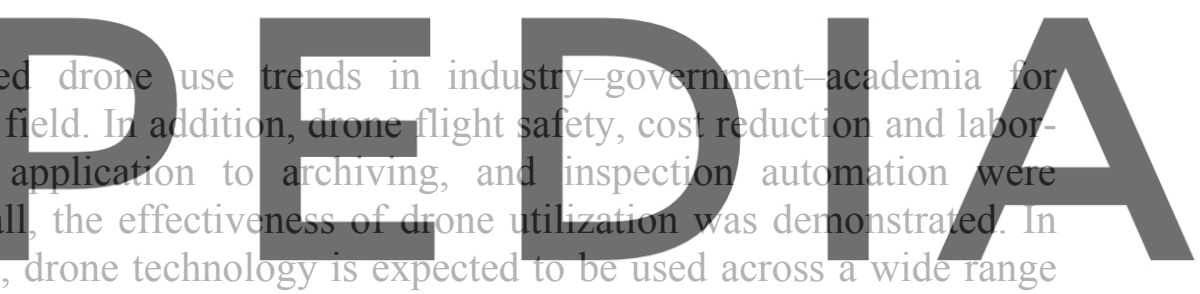
of fields, including disaster surveys, architectural education, information systems, facilities,

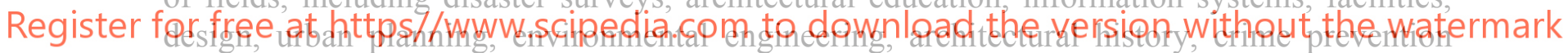
and so on. It will be possible to create a new construction drone platform by strengthening the connected industries that link drones with various technologies (AI, AR, the cloud, etc.). For this purpose, it is very important to work with related parties so that the technology can effectively contribute to society.

\section{ORCID}

Hiroyuki Miyauchi: https://orcid.org/0000-0002-2391-4388

\section{References}

Impress (2018). Drone Business Survey Report 2018. Japan.

Japan Architectural Drone Association (2018). Safety Manual for Drone Utilization in Buildings. Japan.

Ministry of Economy, Trade and Industry (2017). Roadmap for utilization of the drone according to the flight level. Japan.

Ministry of Internal Affairs and Communications (2013). Housing and Land Survey. Japan.

Ministry of Land, Infrastructure, Transport and Tourism (2017-2018). Building standard maintenance promotion project T3. Japan.

Ishida, T. and Miyauchi, H. (2018). Verification of building inspection technology utilizing autopilot UAV by Visual SLAM: Summaries of technical papers of annual meeting, Architectural Institute of Japan. 561-562. 